DOI: 10.17148/IARJSET.2021.8901

\title{
Study Of Curative Herbs as Substitute for Acetaminophen (Tylenol)
}

\author{
Meena Jha $^{1^{*}}$, Asita Elengoe ${ }^{2 *}$ \\ Ph.D. Research Scholar - Department of Biotechnology, Faculty of Science, \\ Lincoln University College, 47301 Petaling Jaya, Selangor, Malaysia ${ }^{1^{*}}$ \\ Associate Professor, Department of Biotechnology, Faculty of Science, \\ Lincoln University College, 47301 Petaling Jaya, Selangor, Malaysia ${ }^{2 *}$
}

\begin{abstract}
Health and disease are two terms we daily come across and we know the importance of good health. Various biochemical reactions are continuously going inside the human body to repair, rejuvenate, refresh and heal our body from the cellular level. It has been observed that nowadays due to tech-savvy lifestyle and to get immediate result people are more dependent on medicines to remain fit. No doubt, medicines give quick relief but we can not ignore \& deny side effects caused after consuming them. Acetaminophen is a drug worldwide used by people as a pain killer, to reduce pain and fever and is easily available in different names like Tylenol, Calpol, Panadol, and Dolo 650 Tablet. Prolong, overdose, or regular use of Acetaminophen may be poisonous and results in chronic effects like anemia, may cause dizziness, skin pallor, light-headedness, fast heartbeat, and may even damage to liver \& kidneys. Very less is known about its pharmacodynamics. Medicinal plants contain particular alkaloids with bioactive compounds which are beneficial for mankind for treating many diseases without causing any harm to our vital organs and they are the ray of hope amidst pandemic time too. Tulsi, Ginger, Turmeric, Neem are easily available everywhere and hence can be used as an effective substitute for Acetaminophen. The study is conducted on rural tribal people of Uttarakhand India. A total of one hundred sixteen respondents were questioned and it was analyzed that $55.2 \%$ of people understand that too much use of paracetamol for extended periods can damage the liver. $45.7 \%$ of people have used plant-based medications for the immediate cure of aches and pains instead of medicines. The study reveals that curative herbs are a better substitute because they possess antioxidants, antibacterial properties because of dissolved alkaloids in them. This study is based on current knowledge of Science and can be easily implementable.
\end{abstract}

Keywords: Acetaminophen; Pharmacodynamics; Curative herbs

\section{INTRODUCTION}

Health is the most necessary aspect of our life. According to WHO, health is the complete state of social, mental, and physical well-being. For staying fit people are now dependent on medications. Acetaminophen is widely used for instant relief from pain but people are unaware of the consequences of overdose[1,2]. In 1893, acetaminophen was first used then its use was stopped due to the likely cause of methemoglobinaemia[3]. The major concern is that Acetaminophen is easily available in all the medical stores across the world and its overdose causes long-term consequences[4]. Its combination with other drugs affects our body. Due to the action of microbes in the body, our body increases the temperature to kill invading bacteria and other pathogens. After consuming Acetaminophen, it is detected by our hypothalamus in the brain and in response to this the brain sends a signal to the defense mechanism of the body like WBCs to kill invading bacteria. The rise in temperature destroys bacteria and acetaminophen lowers body temperature to normal[5].

Acetaminophen is easily available in various names like Tylenol, Paracetamol, Calpol, Panadol, and Dolo 650 Tablets, pills, suspensions, etc. Acetaminophen is popular among all still the proper mechanism of action is debatable. Many theories state that it works like NSAIDs by blocking the cyclo-oxygenase pathways. Nevertheless, it lacks antiinflammatory responses like in the case of NSAIDSs[6]. It has been observed that sometimes in critical fever its use may lead to hypotension[7]. It is, therefore, very important to understand the after-effects and implications for all toddlers \& vulnerable patients like those who are anaemic \& undergoing surgery. However, unlike Aspirin and other strong medicines, it does not interfere with platelets and blood connective tissue. No anti-inflammatory has been observed $[8,9,10]$.

We know that there are various modes of transmission of infectious diseases through air, water, consuming contaminated food, sexual contact, pathogens, vectors, etc. When we fall sick we immediately pop up medicines without knowing the long-term consequences. But we should understand that personal hygiene, balanced diet can ward off many diseases. Since our body's metabolic process is disrupted during an illness, we should take a bland and nutritious diet free from oil 


\section{DOI: 10.17148/IARJSET.2021.8901}

and fats when we are sick because our body needs sufficient energy to overcome weakness and infection caused due to pathogenic actions. In such conditions, easily digestible food full of protective nutrients, vitamins, and minerals must be given to patients for quick recovery. Heavy oily, junk, and fast food do not contain adequate nutrients and do not release essential acids in the stomach and liver that can interfere in the proper treatment and cure. A Balanced diet rich in carbohydrates, proteins, vitamins, fats, roughage, and water if taken properly should act as medicine and will boost up our immunity. So in order to avoid diseases, we always need to take proper precautions. The use of medicinal plants has been done since ancient times for a long. The simplest way to know about any plant is by using our sense organs. The main theme of this research study is to know the valuable use of plant products and their capacity to be used as therapeutics. The aim is to make people aware of the importance of bioactive compounds present in plants. Some medicinal plants are easily available and can be grown in almost all climatic conditions. The plants based medications are highly beneficial to all because they contain bioactive compounds which can help to formulate new therapeutics[11]. For example, the discovery of antimalarial drug Artemisinin is obtained from sweet wormwood, a medicinal plant[12]. Curative herbs are used as substitutes for Acetaminophen to cure fever, aches and pains, and other ailments. The main reason is that plant-based medications have manifold benefits like antibacterial, anti-inflammatory properties. Eradication of causes of diseases like infection, lack of nourishment, genetic abnormalities, doing regular exercise, active participation in outdoor games, avoiding a sedentary lifestyle can lead to good health.

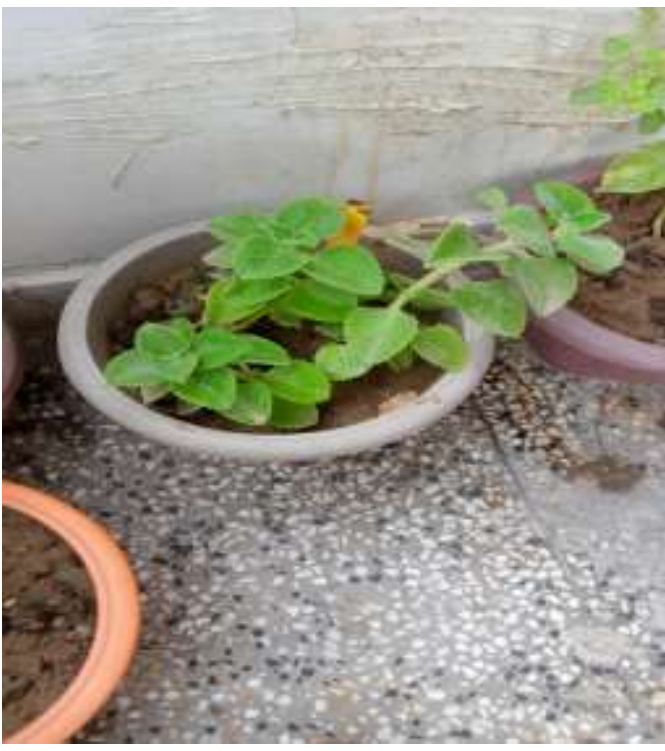

2. METHODOLOGY \& DATA ANALYSIS

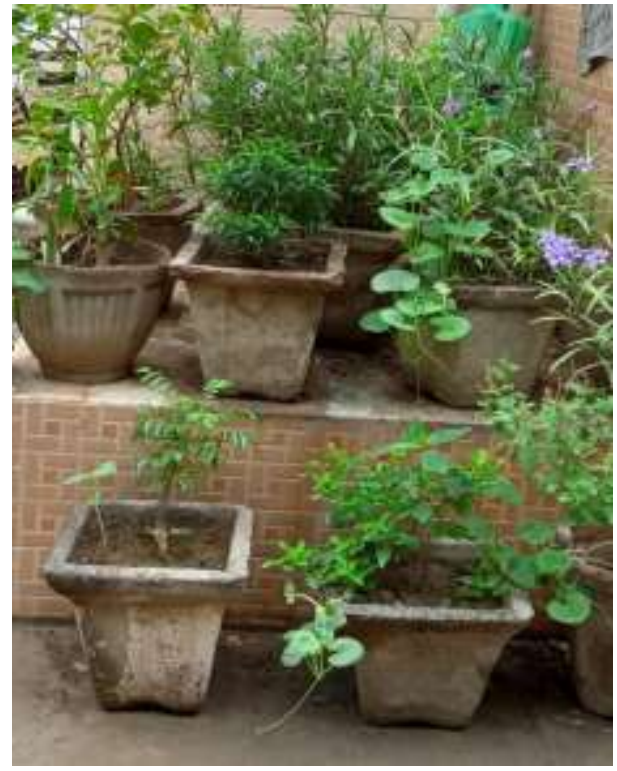

Fig.1. Curative herbs

The online survey study was conducted in Uttarakhand, India, and a total of 116 respondents including adolescents have participated. The questionnaire was about the usage of curative plants as substitutes for Acetaminophen between December 2020 to April 2021 in Uttrakhand, India. 50 objective questions through Google form were framed and asked and distributed online through Whatsapp, emails, and other social sites. Also, telephonically medicos were questioned regarding usages of painkillers. All respondents enthusiastically participated in the survey. The data was collected, the questionnaire was decoded and analyzed using the Google form data analysis.

\section{RESULTS AND DISCUSSION}

The survey shows that most of the respondents are curing themselves by self-medication in order to save time, money, and hospitals long waiting queues. Also, many of them can not deny the importance of plants. 53 out of 116 people rely on plant products for combating health issues. They are using plant roots, rhizomes, branches, twigs, leaves, flowers, and fruits. The herbal tea is popular among folklore of Uttarakhand. In many ancient books, the use of medicinal plants is mentioned to cure diseases. All the plants studied have shown important results and benefits, more research and awareness need to be created and the right message needs to be conveyed to all to pursue more usage of the shoot and root systems of plants. More projects \& programs like Tree plantation drives, conservation of forest should be undertaken and overgrazing, deforestation should be avoided to save flora and fauna. The use of herbal plants should be more encouraged to reduce the long-term side effects and toxicity caused by medicines. 
International Advanced Research Journal in Science, Engineering and Technology

Vol. 8, Issue 9, September 2021

DOI: 10.17148/IARJSET.2021.8901

Acetaminophen (PCM) is one of the most common medicine one would take if you have a headache, if you have fever and generally it reduces fever and you start feeling better. 116 responses

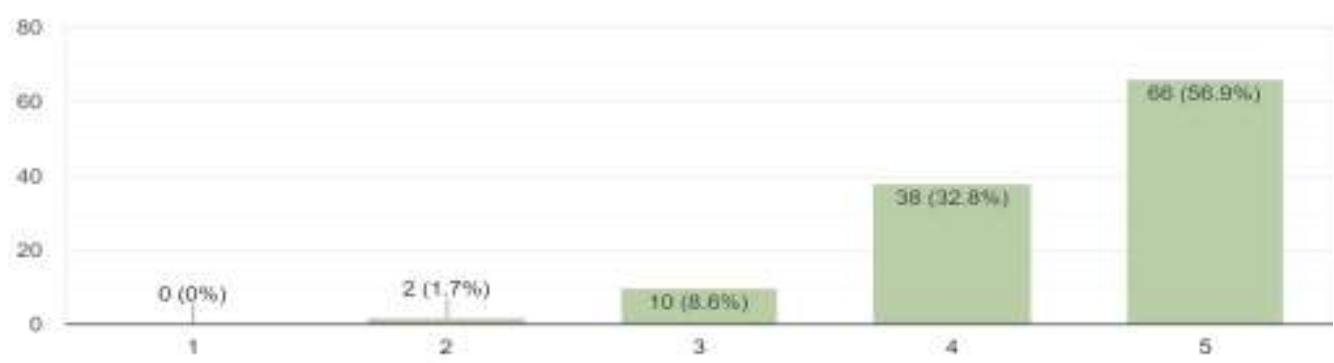

Fig.2: This graph shows that 56.9\% would take Acetaminophen (PCM) when they have fever or Headaches

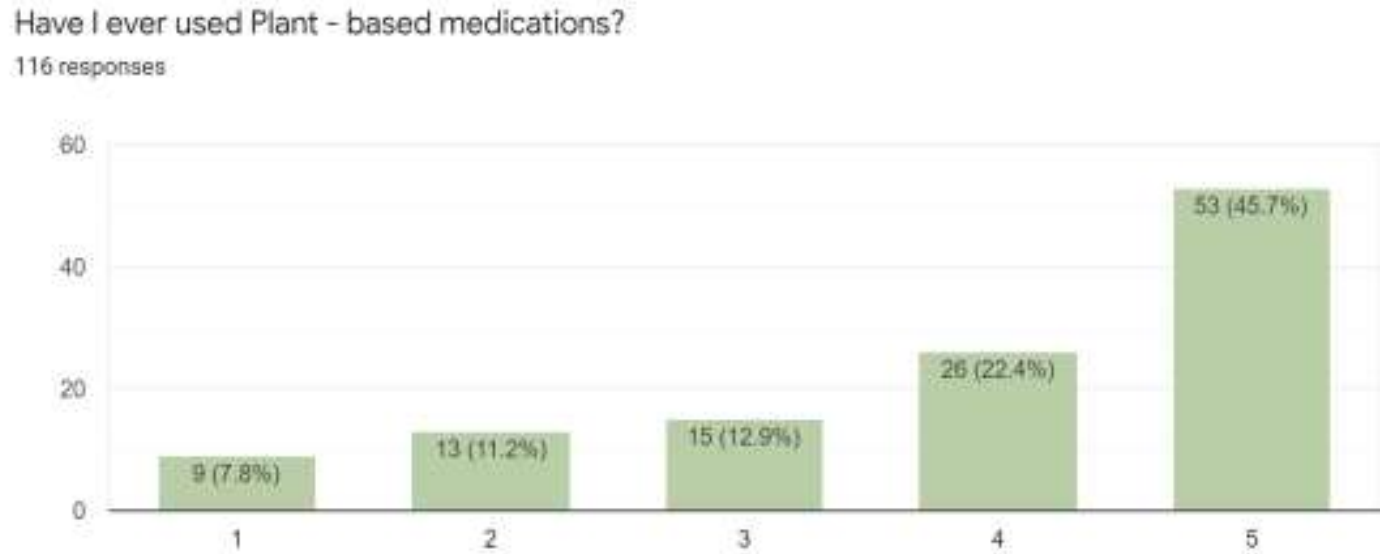

Fig.3: This graph shows that $45.7 \%$ of people have used plant-based medications.

Too much use of Paracetamol for extended periods of time can damage liver.

116 responses

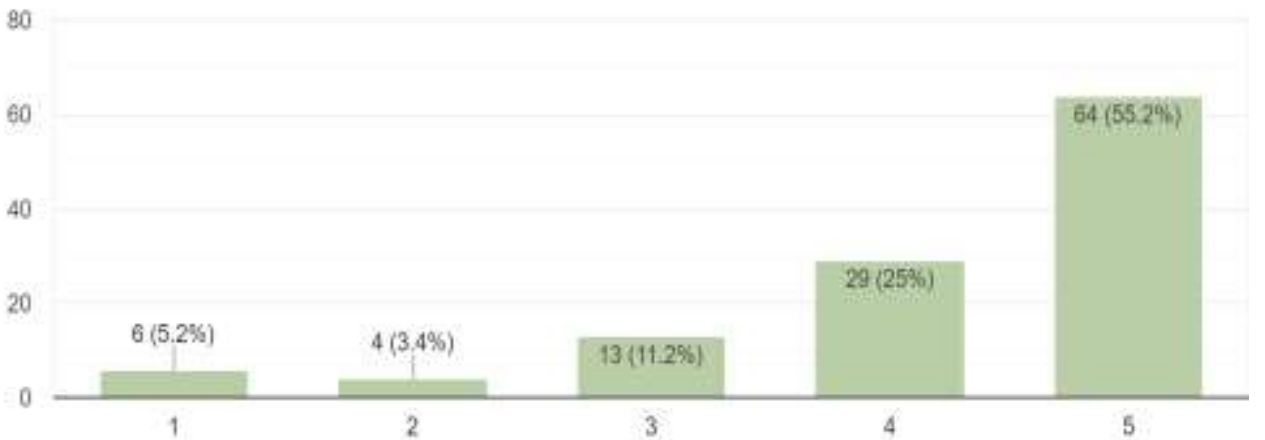

Fig.4: This bar graph shows that $55.2 \%$ of people understand that too much use of paracetamol for extended periods can damage the liver. 


\title{
International Advanced Research Journal in Science, Engineering and Technology
}

\author{
Vol. 8, Issue 9, September 2021
}

\section{DOI: 10.17148/IARJSET.2021.8901}

Despite the fact that medicinal plants have curative and healing properties, their use is often neglected and ignored. The toxicity of synthetic drugs and long-term effects are indeed alarming and making researchers find the substitute of herbs for a solution. The findings of Artemisinin encourage and motivate further researchers to study plant's bioactive compounds. The branch of Science, Biotechnology helps to manufacture effective medicines from plant products which facilitates more production of plant-based drugs[13]. According to WHO, 80\% of people across the world in the tribal areas are dependent on plant-based products for health cures. In Charak Samhita and Vedas mentioned that ancient scholars rely on plant-based medications only. The need of the hour is to create awareness among generation $\mathrm{x}$ and generation z. Plant products can also be used to make cosmetics, perfumes, dyes, fabrics, pest control, etc. Common medicinal plants like Tulsi, Basil, Black Pepper, Ginger, Turmeric, Garlic, Neem are effective in curing many ailments. Herbal tea, containing Ginger, Pepper, Basil gives instant relief from sore throat and cures hoarseness of voice[14]. Most of the synthetic drugs are popular but nature has bestowed many plant herbal products to improve our health naturally without any side effects. For example, Turmeric was used in India for more than 4000 years back and it has many uses like reducing pain, making skin glow, preventing cancer $\&$ arthritis, fighting inflammation, etc $[15,16,17]$.

\section{CONCLUSION}

The study shows the use of acetaminophen is higher for instant relief from aches and pains and knowledge about cautious usage is not good among people. People in Uttrakhand India and others living near forests areas are found to using more medicinal plants due to easy availability and they believe in more ancestral knowledge of plants. Hence, the use of curative herbs should be more promoted and conservation of these plants is important. So it's the moral duty of medicos and medical practitioners to work in unity for the betterment of mankind. The plants discussed here have the capacity of curing ailments so we need to ponder over more plant-based products and we should extract bioactive chemicals from plants for processing into medicines.

\section{ACKNOWLEDGEMENT}

This study work is part of the Ph.D. Doctoral Research work of the principal (first author). Grateful to Uttrakhand respondents $\&$ all medicos for sharing pieces of knowledge and valuable information.

\section{COMPETING INTERESTS}

The authors declare that they have no competing interests.

\section{REFERENCES}

1. Akerele O. in Nature's Medicinal Bounty; don't throw it away. (1993).

2. Bertolini A, Ferrari A, Guerzoni S, Leone S, Ottani A, Tacchi R.paracetamol: new vistas of old drug. (CNS Drug Rev. 2006;12: 250-275).

3. Busuttil RW, Chun LI, Hiatt JR, Tong MJ, (2009) Acetaminophen hepatotoxicity and acute liver failure.

4. Fendrick AM, Greenberg BP. Review on Osteopathic medicine and care. 2009 Dec;3(1):1-7.

5. Global Acetaminophen Market Industry Analysis, Segment Forecasts (2016). https://www.globenewswire.com

6. Graham GG, Day RO, Scott KF, Tolerability of paracetamol. 2005 Mar;28(3):227-40.

7. James LP, Ajay. Acetaminophen: In Drug-Induced Liver Disease 2013 Jan 1 (pp. 331-341). Healing with plants - phytotherapy. Beograd: Culture; 1971 by Academic Press.Tucakov.

8. Ott P, Dalhoff K, Loft S., Hansen P.B.,Poulsen H.E. (1990) Results of the-counter availability of paracetamol in Denmark. https://pubmed.ncbi.nlm.nih.gov >.

9. Petrovska BB. Department of Pharmacognosy. Pharmacognosy reviews. 2012 Jan;6(11):1.

10. Sofowora A, Ogunbodede E, Onayade A. Importance of medicinal plants in the strategies for disease prevention. Published in African journal of Traditional, Complementary, and Alternative medicines. 2013 Aug 14;10(5):210-29.

11. Shen Q, Brodelius P.E, Liao Z, Zhang L.E. The Genome of Artemisia annua, Mol. Plant. 2018;1:776-788. DOI: 10.1016/j. molp. (2018.03.015).

12. Takos AM, F. Rook. Understanding of the molecular biosynthesis of Amaryllidacea alkaloids in medical use. Published in International journal of molecular sciences. 2013 Jun;14(6):11713-41.

13. Tucakov J. Healing with plants - phytotherapy. Beograd: Culture; (1971).

14. Uthaya Kumar U.S., Chen Y., Kanwar J.R., Sasidharan S. Redox control of antioxidant; Oxidative medicine and cellular longevity.(2016) Jan $1 ; 2016$.

15. Vinay Kumar T, Eswar Kumar K, Roy H. Evaluation of antihyperglycemic activity of Citrullus colocynthis streptozotocin-induced in rats having diabetes.

16. Zari ST, Zari TA. Review of medicinal to treat eczema. Medical Plants Research. 2015;9(24):702-11. https://www.semanticscholar.org > paper review.

17. Zuardi AW, Cannabidiol, Crippa JAS, Guimaraes F.S. Hallak JEC, Moreira FA,Cannabis sativa constituent, as an antipsychotic drug. Brazilian Journal Medical Biological Research 2006;39(4):421-9.

18. Pooja Dahiya; Roopsi Kaushik; Anil Sindhu. "Physiological Analysis of Dairy Effluent". International Research Journal on Advanced Science Hub, 2, Special Issue ICAET 11S, 2020, 20-29. doi: 10.47392/irjash.2020.228 